\title{
State regulation of sustainable development municipalities of the region
}

\author{
Larisa Sokolova* and Irina Kazantseva \\ Baikal State University, Irkutsk, Russia
}

\begin{abstract}
The formation of methodological tools for the sustainable development of regions, the formation of an integrated system of strategic planning of socio-economic development at the municipal level is among the least developed topics. On the example of a municipality, the practice of developing strategic planning documents, their compliance with the requirements of the existing regulatory framework, the mechanism for implementing the strategy and ensuring its implementation with financial resources is studied. The factors influencing the formalization of the developed strategic landmarks of the territory are established. The article substantiates the need to supplement the algorithm of strategic planning of socio-economic development of municipalities of the regions with new methods of analyzing the construction of vertical and horizontal economic relations, in order to select options for structural transformations, as well as to determine the resource potential, including labor. Establishment of indicators of goal-setting in the social sphere and its direction.
\end{abstract}

\section{Introduction}

Interest in the developing system of strategic planning in Russia is due, on the one hand, to the practical need to establish clearly defined targets and directions of territorial development, and, on the other hand, to the methodological lack of elaboration of the technology for its implementation. The practice of implementing the federal law "On Strategic Planning in the Russian Federation" [6] over the past five years has revealed a number of methodologically unsolved problems that do not allow building a nationwide system of strategic planning in the Russian Federation. Legally allocated objects of strategic planning - territorial and sectoral levels of management do not have an interaction algorithm on the issues of coordinating the goals and objectives to be solved, on the substantiation of the established criteria for their achievement and the priority of the spheres of social economic development.

An important role in the system of strategic planning belongs to the qualification level of the management apparatus, since, as practice has shown, insufficiently trained in the methods of strategic planning, it is not able to coordinate work to determine competitive advantages in the markets of goods and services, resources, labor potential, a combination of sectoral and territorial planning. As a result, the strategic guidelines for the development

\footnotetext{
* Corresponding author: sokolova-lg@yandex.ru
} 
of the municipality are determined on the basis of the existing system of industrial relations and do not provide for structural changes in economic development.

\section{Research Methodology}

The purpose of this study is a theoretical substantiation of the efficiency of interaction between public authorities, private business [12] and local governments, based on the principles of interaction in the development and implementation of strategic projects for the social-and-economic development of the region.

Currently, there is an active work on the preparation of regulatory documents for the strategic development of activities, Russian Federation constituent entities and municipalities. We will consider the methods of forming the strategic development of the territory applied in practice using the example of the Russian Federation constituent entities, the Siberian Federal District, the Irkutsk Region, which is part of this Federal District and the municipalities located on its territory, representing the Ekhirit-Bulagat municipal district. The existing regulatory framework for the development of strategic documents has been studied in detail, the financial capabilities of the municipality to implement the adopted development strategy and the resource potential of the objects under study have been investigated. The study revealed that the formation of a methodologically grounded holistic system of strategic planning in the Russian Federation is possible through the introduction of new methods for analyzing problem areas of development, which make it possible to determine the directions of social-and-economic development at the municipal level pursuant to the needs of the population and enhance the methodology for calculating the criteria of the goal-setting mechanism

\section{Findings}

The review of scientific and methodological literature in recent years has made it possible to identify a number of factors that had a significant impact on the formation of a new paradigm for the strategic development of the territory of the Russian Federation:

- weakening of the role of the institutional factor, since state institutions have now yielded primacy in the formation of the investment climate in the economic development of the territory by national corporations that have great opportunities for investing capital in the economy [8], the legal status of the directions of strategic development and the relationship between economic and social indicators of development have not been established between higher and lower levels of management, which makes them documents that are not binding $[3,5]$,

- formalization of strategic planning of subjects of lower levels of management, in particular, the municipalities. In the Russian Federation, scientifically grounded groupings of planning subjects based on basic development models are not used in practice: Harvard Business School, model of I. Ansoff, model of G. Steiner or ones proposed by the Russian scientists $[9,11]$.

- the formation of strategic guidelines for the development of municipalities based on the existing system of industrial relations and the level of development of the social sphere, without providing for structural changes in economic and social development [1].

The established factors influencing the process of strategic planning in the Russian Federation determine the transformation of the developed strategic guidelines into a necessary accountable function, the implementation of which is ensured not by indicators of the social-and-economic development of the territory, but by the presence of a formed document set. 
The analysis of compliance with the strategic requirements of the existing regulatory framework of documents at the level of the municipality Ekhirit-Bulagat District of the Irkutsk region (tab. 1) showed their full compliance. It seemed that the municipality has a clear program aimed at improving the living standards of the population and developing the economy in the near future. However, a detailed analysis of the developed documents confirmed all of the above factors that are characteristic of the strategic planning of constituent entities in the Russian Federation. All strategic guidelines for the development of the municipality are determined on the basis of the existing system of industrial relations and do not provide for structural changes in economic development, that is, the revenues of the economy allocated to the budget of the municipality will grow in proportion to inflationary processes.

Table 1. Correspondence of strategic planning documents of the municipality Ekhirit-Bulagat District of the Irkutsk region.

\begin{tabular}{|c|c|}
\hline $\begin{array}{c}\text { Required strategic planning } \\
\text { documents }\end{array}$ & $\begin{array}{c}\text { Strategic planning documents developed in the } \\
\text { municipal } \\
\text { formation }\end{array}$ \\
\hline SED strategy & MF SED strategy until 2030. \\
\hline $\begin{array}{c}\text { Action plan for the implementation of } \\
\text { the SED strategy }\end{array}$ & $\begin{array}{c}\text { Action plan for the implementation of the strategy } \\
\text { MF SED }\end{array}$ \\
\hline $\begin{array}{c}\text { SED forecast for the medium or long } \\
\text { term }\end{array}$ & $\begin{array}{c}\text { Medium-term forecast of the MF SED for } 2019 . \\
\text { and the planning period 2020-2021. }\end{array}$ \\
\hline Long-term budget forecast & Budget forecast of the MF SED until 2022. \\
\hline Municipal programs (MP) & 12 MP \\
\hline
\end{tabular}

Note: Compiled by the authors on the basis of the normative documents of the municipal formation

Pursuant to the developed strategic planning documents, an analysis of their financial support and implementation was performed. The strategic goal was to increase the level and life population quality of the MF "Ekhirit-Bulagat District", without specifying the criteria and indicators that should be achieved as a result of the implementation of the strategy. Four strategic objectives have been established: Ensuring economic growth, social development, infrastructure development and provision of living conditions, as well as regulation and control.

To accomplish this goal and objectives, 12 municipal programs have been developed. The analysis of their financial support (Fig. 1) characterizes the concentration of budgetary resources mainly in the social sector, to ensure the functioning of the existing objects of education, culture, physical culture and sports, etc. After the approval of the strategy of social-and-economic development of the municipality "Ekhirit-Bulagat District", there was no redistribution of financial resources for the implementation of the set strategic goals and it may be stated that the municipal programs are not focused on the implementation of strategic goals and objectives, but are aimed at maintaining the existing structure of the economic structure. The analysis of the action plan for the implementation of the strategy of the social-and-economic development of the municipality confirmed the current trend in the distribution of budgetary resources. It does not highlight the strategic and tactical goals, tasks defined by the strategy, but the actions are compiled in eight sections. The action plan for the implementation of the strategy should be a tool that determines the sequence of achieving goals, solving the tasks of the strategy, that is, the scenario for its implementation. In the municipality under study, the action plan for the implementation of the strategy of social-and-economic development does not fulfill its function. 
Thus, this study showed that in the strategic documents of the social-and-economic development of the municipality. the principle of consistency and balance in priorities, goals, tasks, activities, financial resources has been violated.

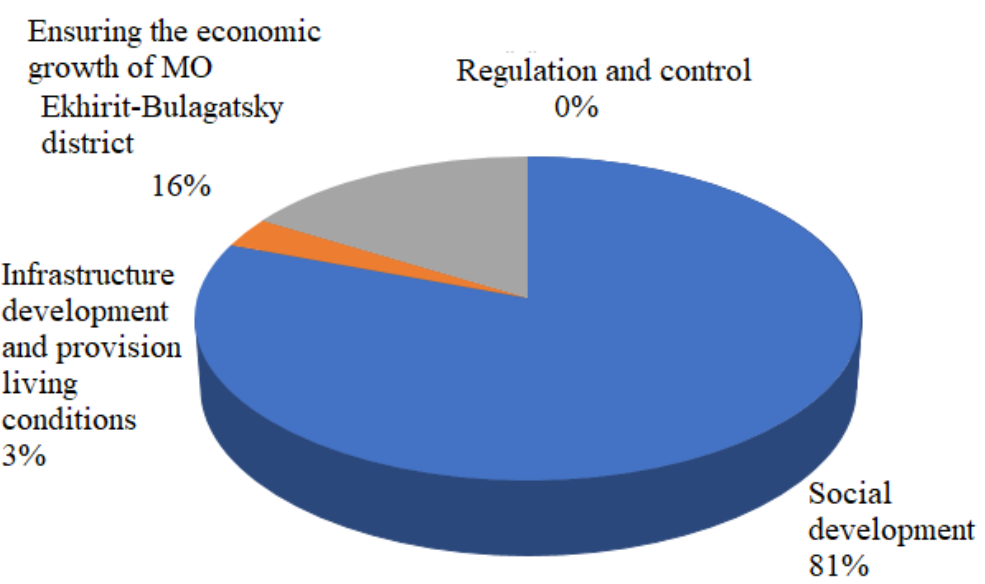

Fig. 1. The structure of expenditures of budgetary resources for the strategic objectives of the municipality "Ekhirit-Bulagat District"

The lack of a mechanism for goal-setting, monitoring of strategic criteria and indicators laid down in municipal programs and an action plan for the implementation of the strategy of social-and-economic development of the municipality not only reduces the significance of the developed documents and presupposes their implementation pursuant to the available financial possibilities, but also affects the level of interaction between the population, business subjects and bodies of local self-government in the process of strategic planning.

\section{Discussion}

The scientific literature proposes numerous variants of the algorithm for developing a strategy at various levels of management, including the technological sequence of performing forecasting and analytical work, special principles of organizing work in municipalities, etc. $[7,1]$. The authors describe in quite detailed way the stages of the formation of strategic documents, developed at the municipal level of management, which ensures their formation, but complicates the implementation and assessment of the planned indicators.

Currently, initial stage of the revival of strategic planning in territorial and sectoral aspects in the Russian Federation, it is advisable to change the concept of strategic planning of regions. Strengthening the institutional factor will make it possible by moving from the preparation of targets for economic and social development in the future pursuant to the current situation. When determining the priorities for sectoral development of spheres of activity, a municipal entity in its strategic development should see its role in solving socialand-economic problems in a constituent entity of the Russian Federation, and a constituent entity of the Russian Federation as a whole in the country [4]. A mechanism is needed that functions in the system of strategic planning on the territory of the Russian Federation, combining territorial and sectoral interaction (Fig. 2). This will allow to identify unique types of activity as "growth poles" or clusters already at the stage of formation of the strategy of the municipality. Establishing vertical and horizontal economic ties prior to the formation of strategic development documents will make it possible to determine the 
industries of specialization, city-forming, dominant ones, to calculate the estimated budget revenues, on the basis of which areas of social development will be planned.

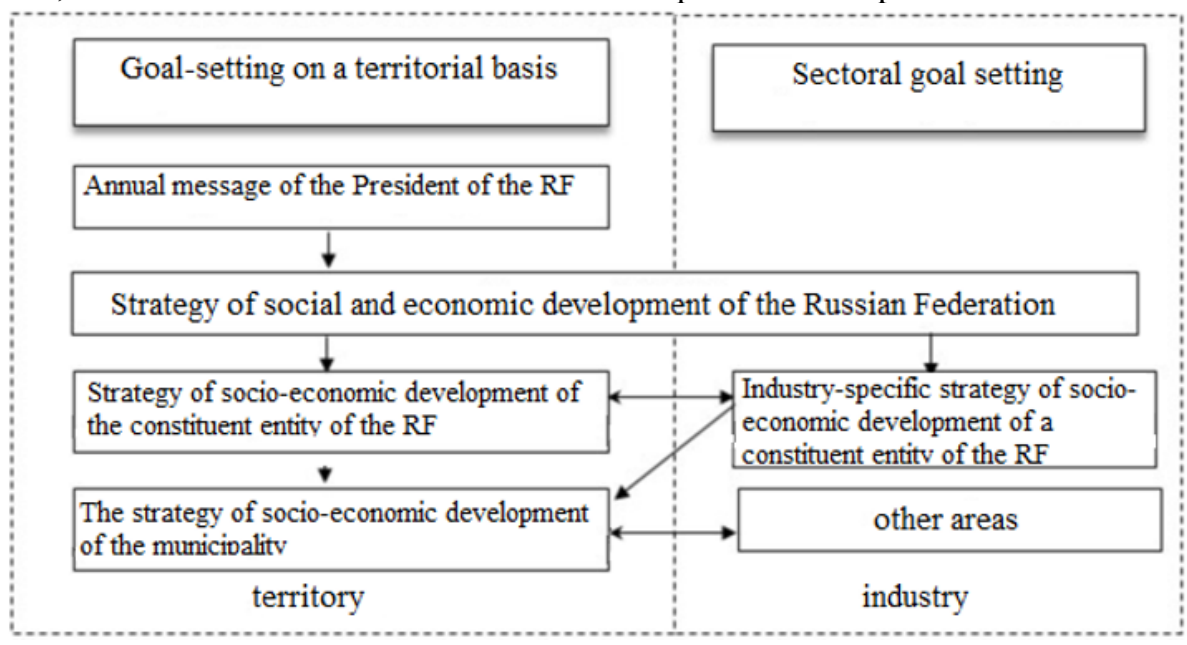

Fig. 2. Dependence of strategic documents at the territorial and sectoral levels of management pursuant to the principles of goal-setting.

In addition to determining additional budget revenues through the development of new types of activities in the territory of the municipality, it is important to determine the resource potential for the implementation of the strategy. Calculations of natural resources, as a rule, are determined for each territory and their use depends on the availability of investors, who will be identified during the coordination of strategies for sectoral and territorial planning. The issue is more complicated considering the strategic directions of labor potential and the accompanying development of social infrastructure. In the Russian Federation, traditionally, the labor potential was calculated using demographic indicators as the basis for its formation. In recent years, a migration policy has developed in the country, concentrating the population in large cities with a developed social infrastructure. In rural and small and medium-sized urban areas, population decline does not contribute to the development of infrastructure for the life support of the population, and municipalities in their development strategies plan to support it at the achieved level. Such a policy for the development of the social aspect of the territorial entity will contribute to the further outflow of the population.

To determine the priorities of the social development of the territory, it would be advisable to apply assessment criteria that characterize the gender reserve. The Russian science has no unified approach to the consideration of gender problems, the practice of regional gender studies and their application in forecasting and strategic planning of the social-and-economic development of a territory has not been developed.

To form indicators of the gender reserve of the territory, both international social criteria and the presence of statistical characteristics of the socio-demographic composition of the population of the Russian Federation were used. To calculate the gender reserve of the territory and determine the priorities of social development, four groups of indicators are proposed that determine health, education, employment and incomes of the population.

The first group of indicators - health, reveals changes in the average life expectancy and the value of the median age of the population.

The second group of indicators - education [2], allows to determine changes in the age and gender composition of the population and the level of education. 
The third group of indicators, employment of the population, sets the level of economic activity.

The fourth group of indicators - income, compares changes in the average monthly salary and the average monthly established pensions by the age and gender composition of the population.

The integral indicator of these four groups of indicators determines the level of lag of the subject from the average. The lower the numerical value of the integral indicator, the higher the level of development of this social sphere.

After calculating the integral indicator of gender balance of the population in four groups in the Russian Federation, in the Russian Federation constituent entities of the Siberian Federal District, the Irkutsk Region and the municipality "Ekhirit-Bulagat District" of the Irkutsk Region, it may be concluded that there is a significant range that currently exists in the development of the social sphere.

Table 2. Calculation of the indicator of the index of gender balance of the population in the Russian Federation constituent entities.

\begin{tabular}{|c|c|c|c|c|c|}
\hline \multirow{2}{*}{$\begin{array}{c}\text { The subject of the } \\
\text { Russian Federation }\end{array}$} & \multicolumn{5}{|c|}{$\begin{array}{c}\text { The value of groups of indicators of the gender balance index, } \\
\text { ordered by the degree of importance }\end{array}$} \\
\cline { 2 - 6 } & education & employment & health & income & Total \\
\hline Russian Federation & 1.38 & 4.76 & 0.36 & 1.23 & 7.73 \\
\hline Siberian Federal District & 3.22 & 3.71 & 1.53 & 6.18 & 14.64 \\
\hline Irkutsk Region & 4.99 & 1.82 & 1.57 & 25.53 & 33.91 \\
\hline $\begin{array}{c}\text { Municipal Formation } \\
\text { "Ekhirit-Bulagat District" } \\
\text { of the } \\
\text { Irkutsk region }\end{array}$ & 11.92 & 41.16 & 1.69 & 47.01 & 101.78 \\
\hline
\end{tabular}

When forming the strategy of the municipality, it may be recommended to include in the action plan for its implementation additional actions to increase the employment of the population and increase its profitability, since these factors may have a negative impact on the outflow of the population from the region.

\section{Conclusions}

The study revealed important problems that arose in the course of the practical implementation of the legislation of the Russian Federation on strategic planning and forecasting, especially at the municipal level of government. The identified problems may be leveled by expanding the algorithm for the development of municipal strategic planning documents at the first stage, strengthening it with new methods of data analysis, choosing a method for calculating goal-setting indicators and evaluating the efficiency of determining the directions of social-and-economic development.

\section{References}

1. V. Babkin, E. M. Bukhvald, Scientific and technical statements of the St. Petersburg State Polytechnic University. Economic sciences 4 (223), 25 (2015)

2. M. E. Baskakova, I. V. Soboleva, Education Issues 4, 83 (2017). DOI 10.17323/18149545-2017-4-83-103.

3. E. M. Buchwald, Vestn. VolSU. Ser. 3: Economics. Ecology 4(37), 41 (2016) 
4. I. M. Golova, A. F. Sukhovey, Economy of the Region 15(4), 1294 (2019). DOI 10.17059/2019-4-25

5. B. S. Zhikharevich, T. K. Pribyshin, Issues of State and Municipal Administration 1, (2018)

6. Law of the Russian Federation "On Strategic Planning in the Russian Federation" dated June 28, $2014 \quad$ No. $172 . \quad$ SPS "ConsultantPlus". http://www.consultant.ru/document/cons_doc_LAW_164841/

7. V.E. Rokhchin, V.A. Gnevko, Spatial Economics 4 (192), 101 (2006)

8. L.G. Sokolova, The use of innovative technologies in the development of a regional development strategy. Strategy for sustainable development of Russian regions: Collection of materials of the XXXYIII All-Russian scientific and practical conference. Ed. S.S. Chernov, 180 p. (Novosibirsk: TsRNS Publishing House, 2017)

9. L.G. Sokolova, R.N. Sheveleva, Features of strategic planning of the socio-economic development of municipalities. Trends and problems in the Russian economy: theoretical and practical aspects: materials of the All-Russian. Conf., Irkutsk, 205 (2017)

10. L.G. Sokolova, I.I. Kazantsev, Bulletin of the Baikal State University 30(4), 541 (2020). DOI: 10.17150/2500-2759.2020.30(4).541-550

11. A. F. Sukhovey, I. M. Golova, Economy of the Region 16(4), 1302 (2020). DOI 10.17059/ekon.reg.2020-4-20.

12. M. Ayaganova, T. Pritvorova, D. Mamrayeva, L. Tashenova, Economic Annals XXI, 178(7-8), 96 (2019). doi: https://doi.org/10.21003/ea.V178-08 